\title{
Optimization of process parameters in series hydraulic hybrid system through multi-objective function
}

\author{
Somashekhar S. Hiremath*, R. Ramakrishnan and M. Singaperumal \\ Department of Mechanical Engineering, Indian Institute of Technology Madras, Chennai, INDIA \\ E-mail: somashekhar@iitm.ac.in, ramakrishnan20@gmail.com,msingam@iitm.ac.in
}

\begin{abstract}
Rising demand, scarcity and lower production rate of crude oil has made fuel an unaffordable for a public passenger vehicle. In this scenario, an energy or fuel efficient system called hybrid system is the hardcore requirement of the automotive industry. The latest gasoline-electric hybrid and hydraulic hybrid systems are significantly more energy and fuel efficient than conventional vehicles. Strength of electric hybrids is its high energy density of electric batteries, allowing for large storage in relatively compact and lightweight batteries. Hydraulic hybrid is the potential technological solution for the limitations in the electric hybrid vehicle. Scalability of hydraulic hybrid system to larger, more powerful vehicles like garbage trucks, passenger bus and delivery trucks when compared to its counterparts. In this paper, a new configuration of the series hydraulic hybrid system has been proposed. The dynamic response of the system is studied using simulation results of the system model in AMESim tool. Sizing of key components in the system involves a parametric optimization with objective function as maximize system energy delivered. However, A trade-off prevails between the system energy consumed and energy delivered. Hence, the process parameters of the system are optimized through multi-objective function. The system simulation results after optimization apparently show that, optimal system parameters significantly improve energy efficiency.
\end{abstract}

Keywords: Series hydraulic hybrid, Multi-objective function, Energy efficiency, Optimization

\section{Introduction}

The American petroleum institute has estimated that, world's crude oil resources ( 2 trillion barrels or $320000 \mathrm{~m}^{3}$ ) would deplete between 2062AD and $2094 \mathrm{AD}$ at a consumption rate of 80 million barrels per day $[1,2]$. The high cost and shortage of crude oil have created an alarm to the crude oil dependent industries such as automobile, construction machinery and agriculture machinery industries to design and develop the energy saving, energy efficient and environmental friendly system. Hence, these companies replace their conventional systems by energy efficient hybrid systems to overcome the current fuel crisis. A hybrid system is a combination of two source of power. The possible combinations include gasoline/hydraulic, gasoline/electric, and fuel cell/battery. Typically, one source is used for conversion of fuel into energy and another source is used as the storage unit. In a conventional vehicle, kinetic energy in the wheel during mechanical friction braking is converted into heat energy and dissipated into atmosphere. But, hybrid system has the capability to regenerate the available kinetic energy for braking into useful energy. This method of regeneration is generally called regenerative braking and it is quite possible in various fields like automobile, construction machinery, and agriculture machinery. Thus, hybrid systems turn out to be a hot topic for research in automotive companies and research institutes all over the world [3].

Generally, these systems can be classified into two categories- electric hybrids and hydraulic hybrids. The most promising hybrid system today is the electric hybrid system, which has two power sources, namely electric battery and internal combustion engine in series or parallel configuration. However, it has a relatively low charging/ discharge rates and also poor regeneration energy saving in contrast to the hydraulic hybrid system [4]. Electric hybrids have their own advantages over their counterparts. This hybrid system has better energy density than hydraulic hybrid system but it has relatively poor power density when compared to its counterpart. Hence, electric hybrid systems can't be potentially used in construction and agriculture machinery, where, power requirements are immense. Hydraulic hybrid system meets high power demand in case of heavy vehicles. These systems can be classified based on configurations into two, namely, parallel and series hydraulic hybrid system [5].

In parallel hydraulic hybrids, input power from prime-mover takes a parallel path via mechanical transmission as well as 
hydraulic transmission to reach the output shaft. These systems have better power transmission efficiency but it has poor controllability of power in the system due to power transmission in two different domains. In case of series hydraulic hybrid system, the input power takes purely a hydraulic domain of power transmission, in spite of this; better controllability of system is possible when compared to parallel configuration $[6,7]$.

Series Hydraulic Hybrid System (SHHS) has got great potential to save the regenerated hydraulic energy as potential energy by compressing the nitrogen gas in the hydro-pneumatic accumulators, hence, creating a relatively higher power density than its counterparts. Moreover, high rates of charging/discharging and lower charging time of regenerated energy makes the SHHS a most energy efficient system [8]. SHHS is a highly non-linear and non-continuous system in which designing physical and process parameters are a complex and tedious process. However, a conflict exists between the input and the output energy which leads to conflicting multiple objective function, that is, maximize energy delivered and minimize energy consumed [9]. In order to design such a system, a multi-objective optimization process is an essential method to achieve optimal physical and process parameters, which results in maximum energy delivered for the minimum energy consumed. In addition to that, it augments the vehicle performance, downsizes the engine, reduce the fuel consumption and also pollution. The multi-objective optimization based on multi-membered multi-criteria evolutionary strategy (MMES) algorithm can effectively decide the optimal system parameters, substantially improve the vehicle performance, and also reduce the power consumption of SHHS in a vehicle.

MMES is one type of evolutionary algorithm used to solve the multiple objective problems and it implements a family of population-based (or: multi-membered) evolution strategies with the mutative self-adaptation of step-size variances. It includes a multi-objective extension of evolution strategies using the non-dominated/crowding distance sorting technique. Furthermore, it is capable of dealing with mixed integer problems by employing specialized variation operators for different parameter types. Main features of MMES include self adaptive refinement of step sizes, handles user defined constraints by objective function penalization, supports mixed discrete/continuous optimization, supports multi objective pareto optimization, allows concurrent evaluation of independent individuals. These features are not commonly found in other methods like gradient-based optimization, simulated annealing and genetic algorithm $[10,11,12]$. In this paper, a multi-objective design optimization procedure based on MMES algorithm, is proposed, which is used to improve the energy efficiency in SHHS is presented. With energy efficiency as a composite function, this procedure decides the process parameters of the system with maximum energy delivered for the given minimum energy consumed. Multi-objective design optimization based on MMES algorithm is discussed in the following paragraphs.

\section{Series hydraulic hybrid system}

Series Hydraulic Hybrid Vehicle (SHHV) is propelled by a system which includes sub-systems such as prime mover (gasoline engine), hydraulic motor/pump, and hydropneumatic accumulator. During braking of vehicle, transmission efficiency of vehicle is enhanced by regenerating the kinetic energy in the wheel into useful hydraulic energy using a hydraulic motor/pump. This regenerated hydraulic energy is stored in the high pressure hydro-pneumatic accumulator and used during the subsequent acceleration of vehicle [13, 14]. A modeling methodology for a hybrid vehicle was proposed in 1997 and then a computer model of series hydraulic hybrid vehicle was developed and investigations focused only on urban passenger vehicle. This study shows that hydraulic hybrid power-train is a feasible concept and fuel economy in addition to emission reduction can be done considerably [15, $16]$.

Figure 1 shows the proposed configuration of the SHHS, which consists of subsystems such as a prime-mover, master hydraulic pump, a hydraulic traction motor, a hydraulic regeneration pump and a hydro-pneumatic accumulator arranged in a series configuration. The prime-mover is directly coupled to a master hydraulic pump, which converts the mechanical energy into hydraulic energy. According to the operating mode, the hydraulic traction motor is driven by the hydraulic energy from the master hydraulic pump as well as hydro-pneumatic accumulator. The hydraulic regeneration pump and hydraulic traction motor are coupled together through a gearbox, which is connected to wheel via a differential.

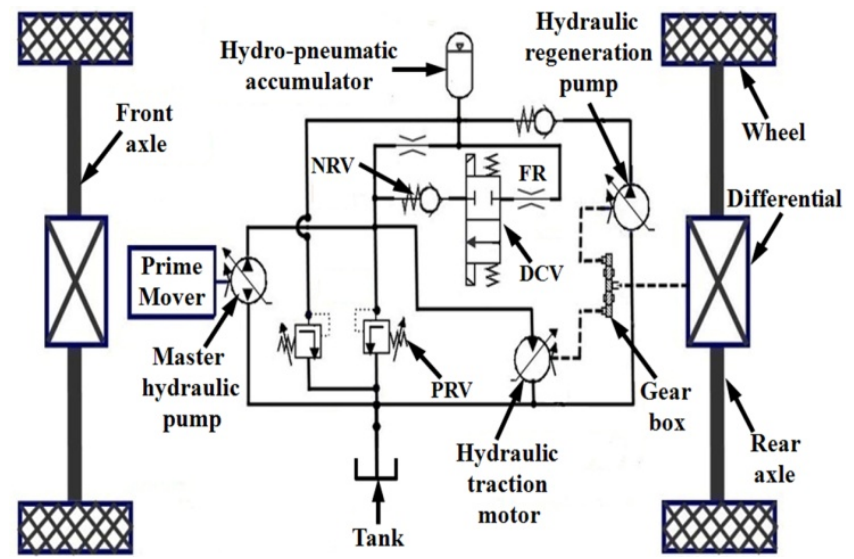

Figure 1: Configuration of series hydraulic hybrid system

The system is divided into three operating modes namely acceleration, cruising and braking mode in a vehicle. When the vehicle is in acceleration mode, energy from two power sources (prime-mover and hydro-pneumatic accumulator) are used to propel the vehicle, that is, hydraulic energy from two sources are supplied simultaneously to power the hydraulic traction motor. During the cruising mode of the vehicle, hydraulic energy from hydro-pneumatic accumulator is cut off and the power from the prime-mover is only used to drive the vehicle. Moreover, the hydropneumatic accumulator is also charged with hydraulic 
energy from the master hydraulic pump. In the braking mode, hydraulic energy from prime-mover and hydropneumatic accumulator is cutoff. An energy recovery method called hydraulic regenerative braking is applied to convert the useless kinetic energy into hydraulic energy. In this method, a new approach called displacement factor control is proposed. It is a process of changing the displacement factor of hydraulic regeneration pump, that is, the increasing in displacement factor proportionately increases the applied torque or load on the hydraulic traction motor. As a result, hydraulic regenerative braking offers resistance to wheel rotation in the vehicle leading to the braking. In addition to that, this method converts kinetic energy in the wheels (usually lost as heat energy due to mechanical friction braking) into useful hydraulic energy.

\subsection{System modeling and simulation}

In order to study the system dynamic characteristics of SHHS, a system model was developed in LMS AMESim tool as shown in Fig. 2.

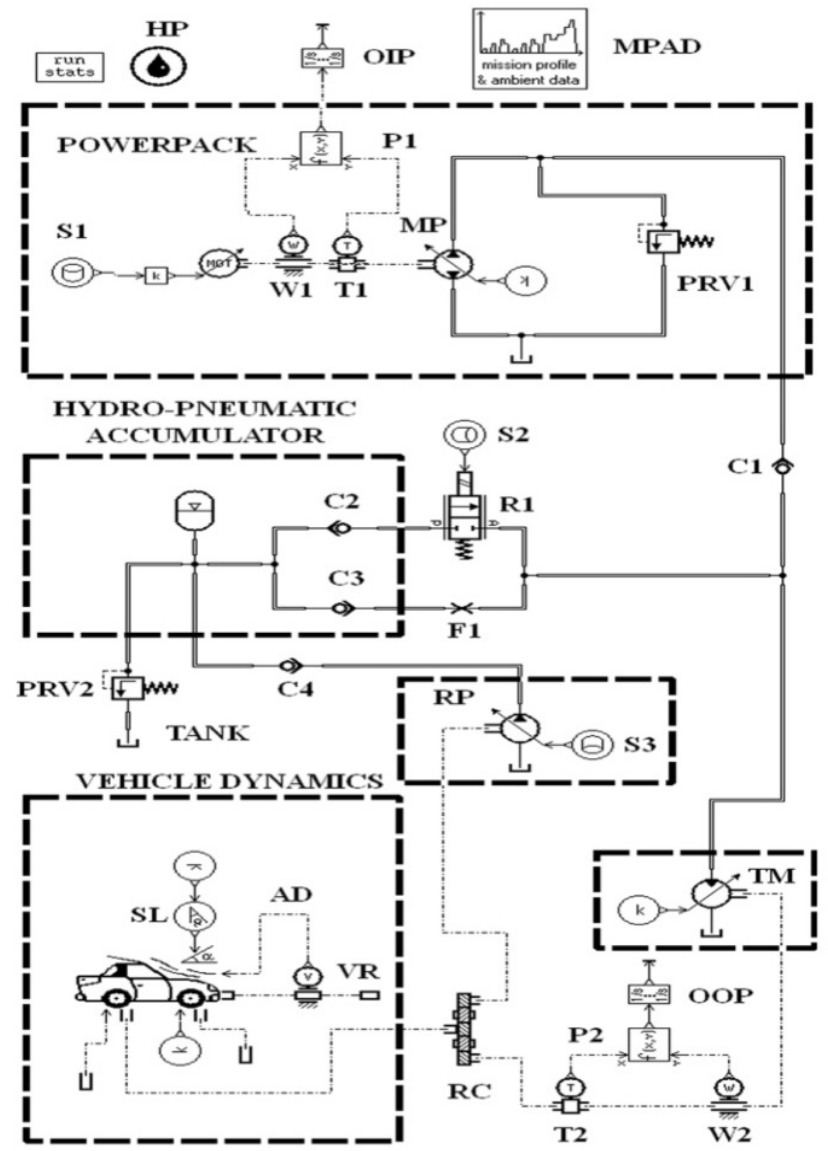

Figure 2: AMESim model of series hydraulic hybrid system

System simulation is carried out with federal urban driving cycle as input to the system [17]. The dynamics characteristic curves of system parameters are plotted as shown in Fig.3. The acceleration mode of the vehicle occurs between $134^{\text {th }}$ and $164^{\text {th }}$ second in the driving cycle. During this acceleration phase, the hydraulic traction motor is powered by the hydraulic energy from the master hydraulic pump and hydraulic accumulator to meet the high power requirements in the vehicle. It is apparent from Fig. 3(a) that, the master hydraulic pump speed increases from 0 to $1620 \mathrm{rpm}$ which enables it to deliver hydraulic energy to hydraulic traction motor. Meanwhile, Hydraulic energy from the hydro-pneumatic accumulator is also discharged, which is noticeable from accumulator flow rate between $134^{\text {th }}$ and $164^{\text {th }}$ second as shown in Fig. 3(b). Furthermore, accumulator hydraulic oil volume decreases from $7.4 \times 10^{-3}$ $\mathrm{m}^{3}$ to $7.0 \times 10^{-3} \mathrm{~m}^{3}$ as shown in Fig. 3(c) for the corresponding change in accumulator oil pressure from 13.1 $\mathrm{MPa}$ to $12.3 \mathrm{MPa}$ as shown in and Fig. 3(d). It is also observed from Fig. 3(e) that hydraulic traction motor speed increases from 0 to $1180 \mathrm{rpm}$ for the corresponding power from the two sources. Therefore, this substantiates that, the prime-mover as well as hydro-pneumatic accumulator simultaneously delivers the power to the hydraulic traction motor in the acceleration mode of system.

In the braking phase of the vehicle between $460^{\text {th }}$ and $495^{\text {th }}$ second of the driving cycle time, hydro-pneumatic accumulator volume compresses adiabatically from $0.4 \times 10^{-3} \mathrm{~m}^{3}$ to $5.8 \times 10^{-3} \mathrm{~m}^{3}$ as shown in Fig. $3(\mathrm{c})$. At the same time, pressure also rises from 5.2 $\mathrm{MPa}$ to $10.1 \mathrm{MPa}$ as shown in Fig. 3(d). It is observed from the above response that, $5.4 \times 10^{-3} \mathrm{~m}^{3}$ of hydraulic oil volume is stored in to the hydro-pneumatic accumulator.

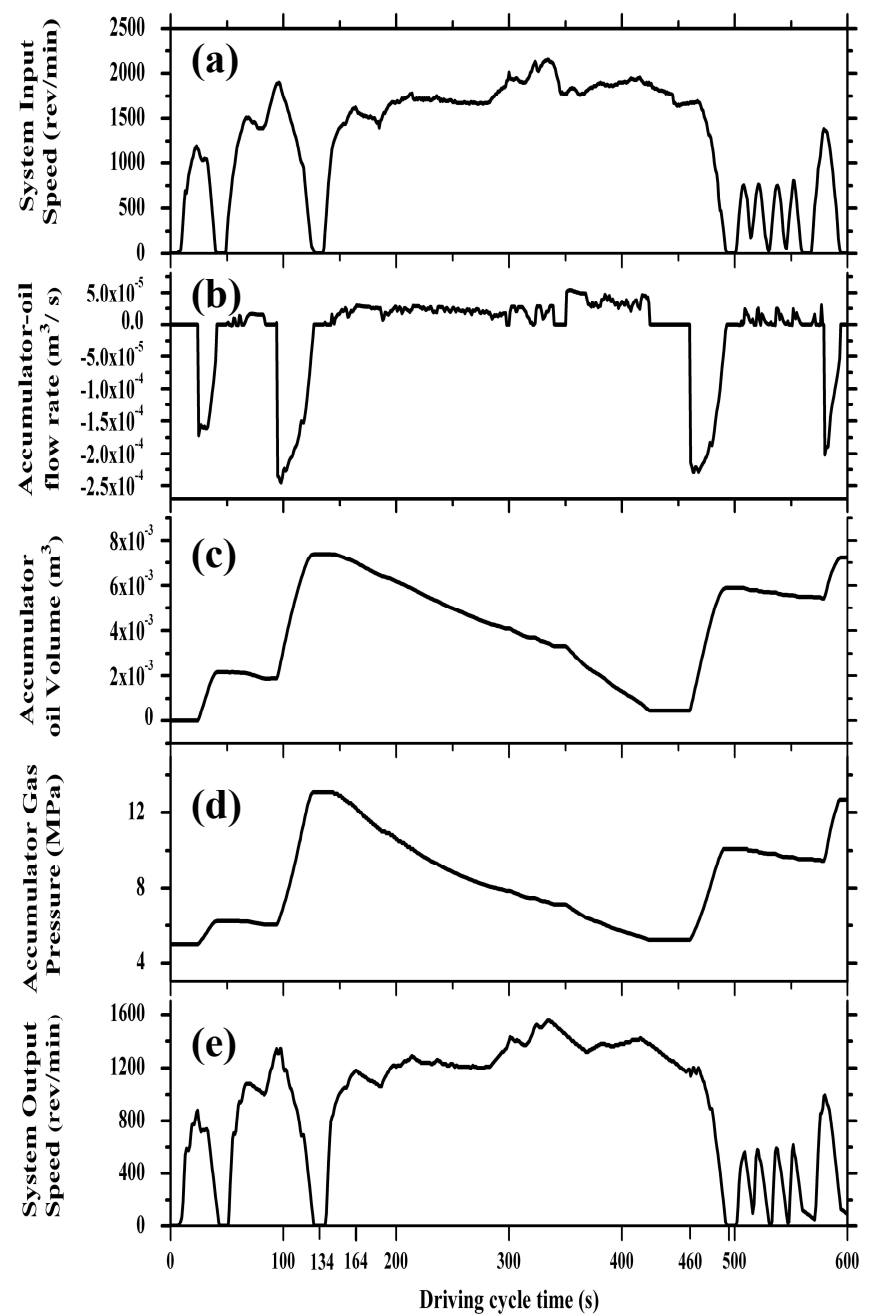

Figure 3: Variation of system parameters Vs driving cycle 


\section{Multi-objective optimization of system process parameters}

In case of SHHS, non-optimal physical/process parameters like accumulator size, accumulator pre-charge pressure volumetric displacement of traction motor, master hydraulic pump and regeneration hydraulic pump have an effect on system energy efficiency [18]. Apart from this, losses due to hydraulic leakage, mechanical friction losses and poor controllability reduce the system output energy or energy efficiency. In spite of these factors, vehicle performance becomes very poor. Even though, the energy delivered by the system can be enhanced by increasing the system energy consumed, but the objective is to reduce the power consumption or energy consumed by the system, so that, potential downsizing of a prime-mover can be attained. However, when the energy consumed by the system is reduced, subsequently there will be a decline in the delivered energy by the system. Therefore, reciprocity exists between energy consumed and energy delivered by the system. Here, an attempt is made to design the system in order to maximize the energy delivery and also subsequently minimize the energy consumed by optimizing the system physical/process parameters.

Figure 4 shows the energy distribution in the SHHS. Energy consumed and energy delivered are the cumulative energy available at the input and output of the system respectively. Energy delivered by the system includes the energy used to drive the vehicle or work done and regeneration energy from hydraulic regenerative braking. Energy consumed for hydraulic regenerative braking and vehicle driving are shown in Eq.1and Eq.2. The output power at traction hydraulic motor is equivalent to sum of power consumed for driving the vehicle and hydraulic regenerative braking as shown in Eq. 3. The multi-objective functions are shown in Eq 4 and Eq.5.

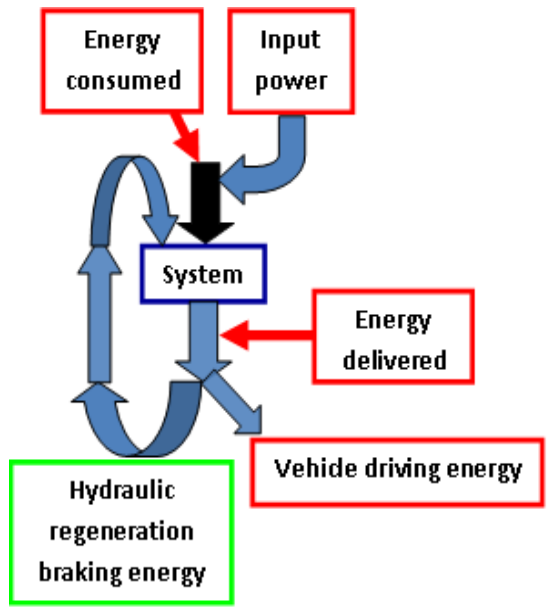

\section{Figure 4: System energy distribution}

The composite function is formulated as the energy efficiency as shown in Eq.6, which is a ratio of system energy delivered to the system energy consumed. Energy efficiency parameter is used to select the optimal Design ID (ID corresponds to design parameter set and their value) or global optimum point from the pareto optimal front.

$$
\begin{aligned}
& \text { Maximize regeneration energy, } E_{R P}=\int_{0}^{T} P_{R P} d t \\
& \text { Maximize vehicle driving energy, } E_{D E}=\int_{0}^{T} P_{D E} d t \\
& P_{T M}=P_{R P}+P_{D E} \\
& \text { Maximize energy delivered, } E_{T M}=\int_{0}^{T} P_{T M} d t \\
& \text { Minimize energy consumed, } E_{M P}=\int_{0}^{T} P_{M P} d t \\
& \text { Maximize energy efficiency, } \eta_{E E}=\left(\frac{E_{T M}}{E_{M P}}\right) \times 100
\end{aligned}
$$

Figure 5 shows the schematic of multi-objective architecture of SHHS. Accumulator pre-charge pressure, accumulator size, master hydraulic pump displacement, hydraulic traction motor displacement and regeneration pump displacement are considered as input variables to the mathematical model in the AMESim. A set of random values (design ID) of these parameters with lower, upper boundaries and step size are sent from the Design of Experiments (DOE) to the MMES scheduler in the process loop as shown in the schematic diagram. The MMES scheduler in turn schedules the order of design ID's to the mathematical model.

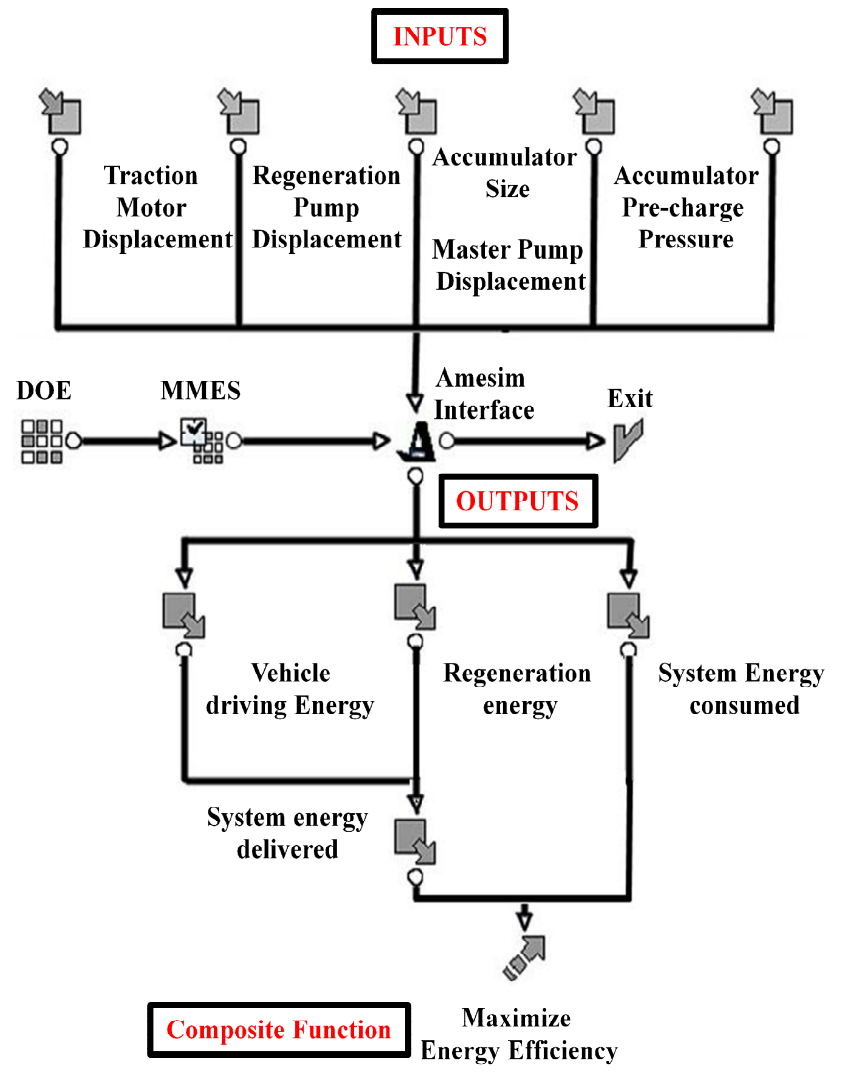

Figure 5: Input-Output architecture of SHHS in multiobjective optimisation

The system simulations are carried out for each set of input variables (design variables) to determine the output 
variables, that is, input and output energy of the system. Pareto optimization of SHHS is carried out using Mode Frontier tool $[19,20]$ with lower and upper limit of input variables considered for optimization as shown in Table 1.

Table 1: Lower and upper limit of input variables considered for optimization.

\begin{tabular}{|c|c|c|c|}
\hline Input variables & Lower limit & Upper limit & Step size \\
\hline $\begin{array}{l}\text { Accumulator size } \\
\left(\mathrm{m}^{3}\right)\end{array}$ & 0.01 & 0.02 & 0.001 \\
\hline $\begin{array}{l}\text { Initial } \\
\text { accumulator gas } \\
\text { pressure }(\mathrm{MPa})\end{array}$ & 9 & 11 & 0.2 \\
\hline $\begin{array}{l}\text { Accumulator pre } \\
\text { charge pressure } \\
(\mathrm{MPa})\end{array}$ & 8 & 10 & 0.2 \\
\hline $\begin{array}{l}\text { Master hydraulic } \\
\text { pump- } \\
\text { displacement } \\
\left(\mathrm{m}^{3} / \mathrm{rev}\right)\end{array}$ & $3.5 \times 10^{-5}$ & $5.5 \times 10^{-5}$ & $2 \times 10^{-6}$ \\
\hline $\begin{array}{l}\text { Regeneration } \\
\text { hydraulic pump- } \\
\text { displacement } \\
\left(\mathrm{m}^{3} / \mathrm{rev}\right)\end{array}$ & $1 \times 10^{-5}$ & $2 \times 10^{-5}$ & $1 \times 10^{-6}$ \\
\hline $\begin{array}{l}\text { Hydraulic } \\
\text { traction motor - } \\
\text { displacement } \\
\left(\mathrm{m}^{3} / \mathrm{rev}\right)\end{array}$ & $5.2 \times 10^{-5}$ & $7.2 \times 10^{-5}$ & $2 \times 10^{-6}$ \\
\hline
\end{tabular}

Multi-criteria optimization results are highlighted and discussed in the following paragraphs. The results of multiple objective functions are plotted in pareto optimal front, which consists of pareto optimal points denoted as design ID. Figure 6 shows the pareto optimal front of multiobjective functions (energy delivered and energy consumed) of system. The selection of global optimum from a pareto optimal front is a complex process because all the points in pareto front are optimal solutions, however selecting the best solution out of all optimal solution is intricate. In order to select the global optimum, a composite function called maximize energy efficiency is considered, which satisfies the multi-objective functions in order to determine the best solution out of all optimal solutions.

Figure 7 shows the energy efficiency of the system versus design ID. Design ID - 119, which as maximum energy efficiency of $94 \%$ is selected as the global optimum point from the pareto optimal front. It is apparent from the pareto optimal front that multi-objective optimization based on MMES converges the pareto optimal points towards a global optimum point, where in, the system delivers $4606 \mathrm{~kJ}$ of energy for the $4900 \mathrm{~kJ}$ of energy consumed. This pareto optimal point satisfies the multiple objective functions as maximum energy delivered for minimum energy consumed. Parameter values of design variables as shown in Table 2 are incorporated in to the AMESim model and system simulation is repeated.

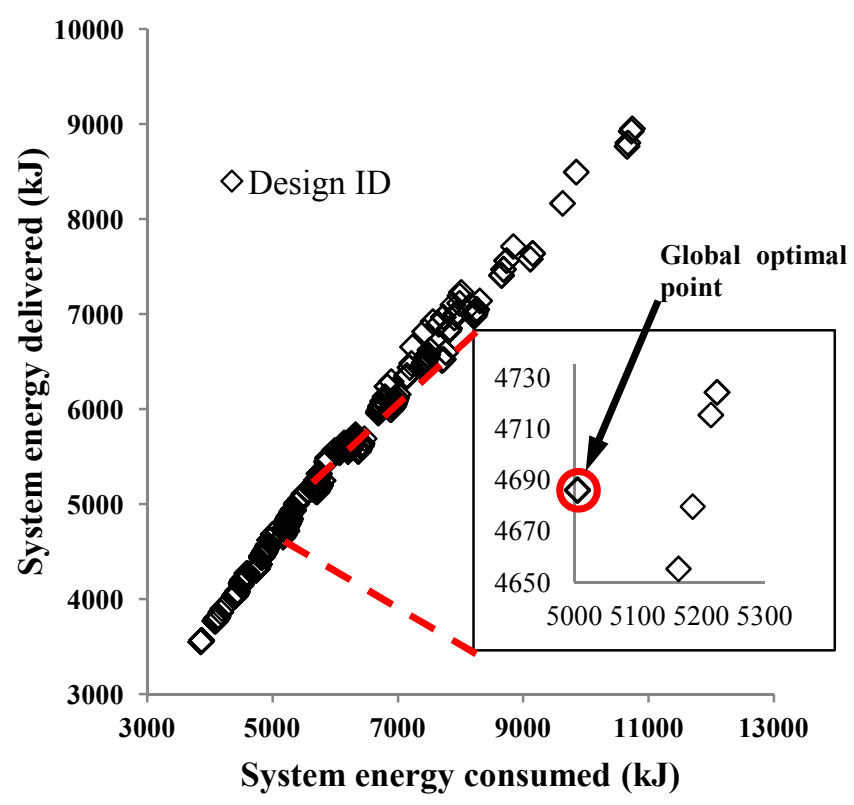

Figure: 6 Pareto optimal front of multi-objective functions

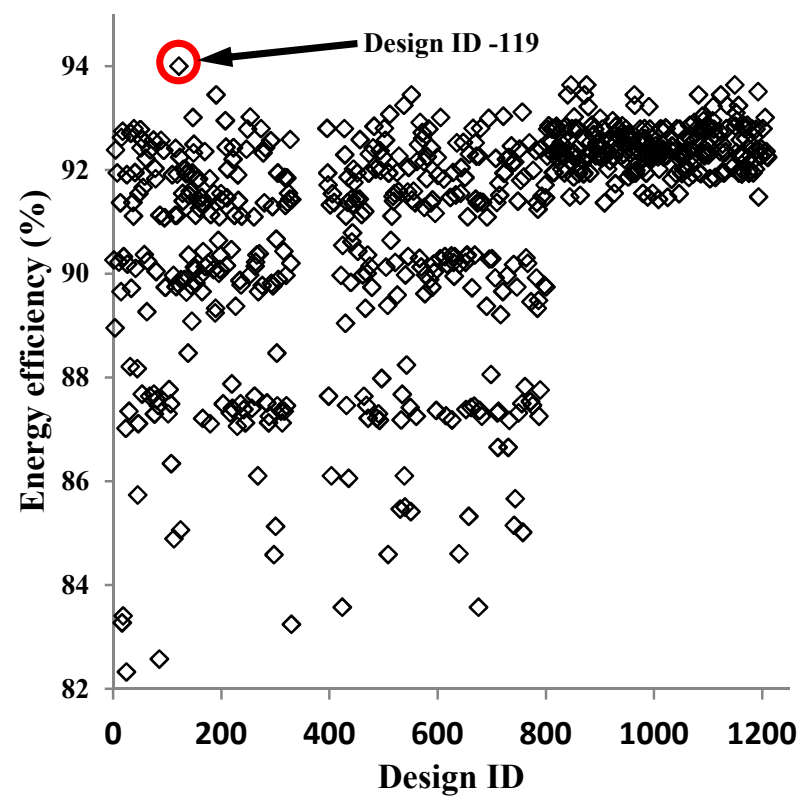

Figure: 7 System energy efficiency $V$ s design ID

Figure 8 shows the difference of system energy between before and after optimization of series hydraulic hybrid system. It is observed from the plot that, the system energy efficiency after optimization has increased by $4 \%$ from the initial value of $90 \%$ before optimization to $94 \%$ after optimization. Due to the increase in energy efficiency, It is clear that, it will facilitate better vehicle performance in optimized SHHS. Moreover, it also facilitates potential downsizing of prime-mover, reduction in power consumption and environmental pollution is possible due to lower energy consumption. Thus, a multi-objective design optimization of process parameters determines the optimal process parameters of series hydraulic hybrid system, which is used to improve the energy efficiency of SHHS. 
Table 2 Optimal design parameters values in optimal design ID 119

\begin{tabular}{|l|l|l|}
\hline Design Variables & $\begin{array}{l}\text { Optimum } \\
\text { value }\end{array}$ & $\begin{array}{l}\text { Before } \\
\text { optimization }\end{array}$ \\
\hline Accumulator volume $\left(\mathrm{m}^{3}\right)$ & 0.013 & 0.015 \\
\hline $\begin{array}{l}\text { Accumulator pre charge } \\
\text { pressure (MPa) }\end{array}$ & 3 & 3 \\
\hline $\begin{array}{l}\text { Master hydraulic Pump- } \\
\text { displacement }\left(\mathrm{m}^{3} / \mathrm{rev}\right)\end{array}$ & $4.0 \times 10^{-5}$ & $4.5 \times 10^{-5}$ \\
\hline $\begin{array}{l}\text { Regeneration hydraulic } \\
\text { Pump- displacement } \\
\left(\mathrm{m}^{3} / \text { rev) }\right.\end{array}$ & $1.75 \times 10^{-5}$ & $2.5 \times 10^{-5}$ \\
\hline $\begin{array}{l}\text { Hydraulic traction motor }- \\
\text { displacement }\left(\mathrm{m}^{3} / \text { rev) }\right.\end{array}$ & $9.3 \times 10^{-5}$ & $8.8 \times 10^{-5}$ \\
\hline
\end{tabular}

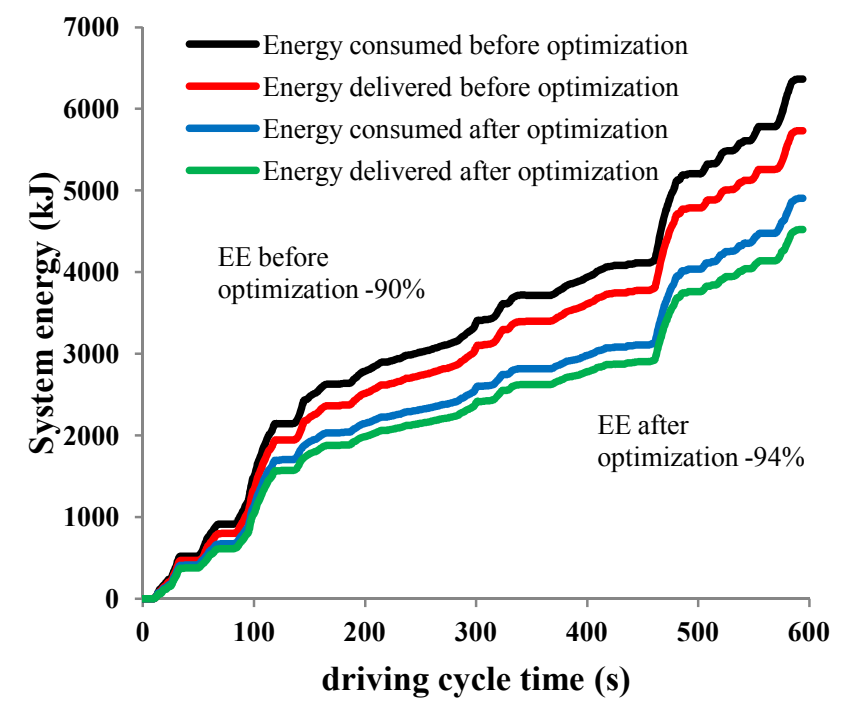

Figure: 8 System energy before and after optimization

\section{Conclusions}

The need for series hydraulic hybrid system arises from world's concern about non- availability of natural resources. In this paper, a multi-objective design optimization of process parameters based on multi-membered multiobjective evolutionary strategy has been carried out to attain better energy efficiency and energy saving. The optimal design ID with maximum energy efficiency of $94 \%$ is obtained as global optimum point in the pareto optimal front and it corresponds to $4606 \mathrm{~kJ}$ of energy delivered for 4900 $\mathrm{kJ}$ of energy consumed. The system simulation with optimal parameters shows that $4 \%$ increase in energy efficiency in comparison with non-optimized system. As the fourwheelers majorly contribute to the world's vehicle population, implementation of series hydraulic hybrid system in these vehicles enhances performance, hydraulic regeneration energy saving, dramatic reduction in power consumption (downsize the prime-mover) and environmental pollution.

Nomenclature

\begin{tabular}{|c|c|c|}
\hline Designation & Denotation & Unit \\
\hline$E_{T M}$ & Energy delivered from the system & {$[\mathrm{kJ}]$} \\
\hline$P_{T M}$ & $\begin{array}{l}\text { System output power or actual power } \\
\text { delivered by motor }\end{array}$ & {$[\mathrm{kW}]$} \\
\hline$P_{M P}$ & $\begin{array}{l}\text { System input power or actual power } \\
\text { delivered to master hydraulic pump }\end{array}$ & {$[\mathrm{kW}]$} \\
\hline$T_{M P}$ & Actual torque delivered to the pump & {$[\mathrm{Nm}]$} \\
\hline$T_{T M}$ & Actual torque delivered by the motor & {$[\mathrm{Nm}]$} \\
\hline$\eta_{\text {отм }}$ & $\begin{array}{l}\text { Overall efficiency of hydraulic } \\
\text { traction motor }\end{array}$ & {$[\%]$} \\
\hline$\eta_{O M P}$ & $\begin{array}{l}\text { Overall efficiency of master hydraulic } \\
\text { pump }\end{array}$ & {$[\%]$} \\
\hline$V_{0}$ & Hydraulic accumulator volume or size & {$\left[\mathrm{m}^{3}\right]$} \\
\hline$p_{0}$ & $\begin{array}{l}\text { Hydraulic accumulator pre-charge } \\
\text { pressure }\end{array}$ & {$[\mathrm{Pa}]$} \\
\hline$D_{M P}$ & $\begin{array}{l}\text { Volumetric displacement of master } \\
\text { hydraulic pump }\end{array}$ & {$\left[\mathrm{m}^{3} / \mathrm{rev}\right]$} \\
\hline$D_{T M}$ & $\begin{array}{l}\text { Volumetric displacement of hydraulic } \\
\text { traction motor }\end{array}$ & {$\left[\mathrm{m}^{3} / \mathrm{rev}\right]$} \\
\hline$\omega_{\text {in }}$ & System input speed & {$[\mathrm{rad} / \mathrm{s}]$} \\
\hline$\omega_{\text {out }}$ & System output speed & {$[\mathrm{rad} / \mathrm{s}]$} \\
\hline$\eta_{v M P}$ & $\begin{array}{l}\text { Volumetric efficiency of master } \\
\text { hydraulic pump }\end{array}$ & {$[\%]$} \\
\hline$\eta_{v T M}$ & $\begin{array}{l}\text { Volumetric efficiency of hydraulic } \\
\text { traction motor }\end{array}$ & {$[\%]$} \\
\hline$p_{\text {gas }}$ & Hydraulic accumulator gas pressure & {$[\mathrm{Pa}]$} \\
\hline$p_{\text {atm }}$ & Atmospheric pressure & {$[\mathrm{Pa}]$} \\
\hline$\rho_{0}$ & Density of hydraulic oil & {$\left[\mathrm{kg} / \mathrm{m}^{3}\right]$} \\
\hline$\rho_{\text {gas }}$ & Density of hydraulic accumulator gas & {$\left[\mathrm{kg} / \mathrm{m}^{3}\right]$} \\
\hline$D_{R P}$ & $\begin{array}{l}\text { Volumetric displacement of hydraulic } \\
\text { regeneration pump }\end{array}$ & {$\left[\mathrm{m}^{3} / \mathrm{rev}\right]$} \\
\hline$\eta_{\mathrm{vRP}}$ & $\begin{array}{l}\text { Volumetric efficiency of hydraulic } \\
\text { regeneration pump }\end{array}$ & {$[\%]$} \\
\hline $\mathrm{t}$ & Driving cycle time & {$[\mathrm{s}]$} \\
\hline$M P$ & Master hydraulic pump & \\
\hline$R P$ & Hydraulic regeneration pump & \\
\hline$F R$ & Flow restrictor & \\
\hline$D C V$ & Directional control valve & \\
\hline$N R V$ & Non return valve & \\
\hline$T M$ & Hydraulic traction motor & \\
\hline S1 & Prime-mover control signal & \\
\hline$S 2$ & Control signal to R1 & \\
\hline$S 3$ & Braking signal & \\
\hline$W 1, W 2$ & Angular velocity sensor $1 \& 2$ & \\
\hline$T 1, T 2$ & Torque sensor $1 \& 2$ & \\
\hline
\end{tabular}




$\begin{array}{ll}C 1, C 2, C 3, C 4 & \text { Non return valve } 1,2,3 \& 4 \\ F 1 & \text { Flow control valve } 1 \\ R 1 & \begin{array}{l}2 / 2 \text { Directional control proportional } \\ \text { valve }\end{array} \\ P R V 1 & \text { Pressure relief valve } 1 \\ P R V 2 & \text { Pressure relief valve } 2 \\ P 1 & \text { System input power } \\ P 2 & \text { System output power } \\ O I P & \text { Energy input } \\ O O P & \text { Energy output } \\ A D & \text { Aerodynamic resistance } \\ S L & \text { Slope of the road } \\ V R & \text { Linear velocity sensor } \\ R C & \text { Rotary node (T-Bevel gear box) } \\ H P & \text { Hydraulic oil properties } \\ M P A D & \text { Driving cycle } \\ \eta_{E E} & \text { System energy efficiency }\end{array}$

\section{References}

[1] Allen E. Fuhs. Hybrid vehicles and the future of personal transportation, CRC Press, 2009.

[2] Davis S C, Diegel S W. Transportation Energy Data book. Center for transportation analysis engineering science and technology division. $24^{\text {th }}$ ed. Oak Ridge National Laboratory; 2004.

[3] Karden E., S. Ploumen, B. Fricke, T. Miller and K. Snyder. Energy storage devices for future hybrid electric vehicle, Journal of Power Sources, 168:2-11, 2007.

[4] Clement-Nyns K. Impact of plug-in hybrid electric vehicles on the electricity system. $\mathrm{PhD}$ Thesis. Katholieke Universiteit Leuven ; 205, 2010.

[5] Baseley, S., Ehret, C., Greif, E., and Kliffken, M., Hydraulic Hybrid Systems for Commercial Vehicles, SAE Technical Paper 2007-01-4150, 2007, doi:10.4271/2007-01-4150.

[6] Hui, S., Jihai, J. and Xin, W. Torque control strategy for a parallel hydraulic hybrid vehicle, Journal of Terramechanics, 46(6): 259-265, 2009.

[7] Wu, B., Lin, C.-C., Filipi, Z., Peng H., Assanis, D. Optimal Power Management for a Hydraulic Hybrid Delivery Truck , Journal of Vehicle System Dynamics, 42(1): 23-40, 2004..

[8] Van de Ven J D, Olson M W; Li P Y. Development of a hydro-mechanical hydraulic hybrid drive train with independent wheel torque control for urban passenger vehicle. Proceedings of the International Fluid Power Exposition, Las Vegas, Nevada; 2008.

[9] Filipi, Z. and Kim, Y. J. Hydraulic Hybrid Propulsion for Heavy Vehicles: Combining the Simulation and Engine-in-the-Loop Techniques to Maximize the Fuel Economy and Emission Benefits, Les Rencontres Scientifiques de l'IFP, Advances in Hybrid Powertrains , 2008.

[10]Hui S , "Multi-objective optimization for hydraulic hybrid vehicle based on adaptive simulated annealing genetic algorithm", Engineering Applications of Artificial Intelligence, 23:27-33, 2010.

[11]Black T , An overview of parameter control methods by self-adaptation in evolutionary algorithms, Fundamenta Informaticae, 35:51-66,1998.

[12]Ajith Abraham, Lakhmi Jain and Robert Goldberg (Eds.), Evolutionary Multiobjective OptimizationTheoretical Advances and Applications, Springer, Berlin, 2005. ISBN 978-1-84628-137-2.

[13] Ramakrishnan R., Somashekhar S. Hiremath and M. Singaperumal. Power bond graph modeling of series hydraulic hybrid system, International Conference on Fluid Mechanics and Fluid Power, IIT Madras, Chennai, 608:1-8, 2010.

[14] Young Jae Kim and Zoran Filipi, "Series Hydraulic Hybrid Propulsion for a Light Truck -Optimizing the Thermostatic Power Management, Soceity of Automobile Engineerings, 24:1597-1609, 2007.

[15]Elder F.T. and D.R. Otis. Simulation of a hydraulic hybrid powertrain, American Society Of Mechanical Engineers, 73-ICT-50, 1973.

[16] Young Jae Kim and Zoran Filipi, "Simulation Study of a Series Hydraulic Hybrid Propulsion System for a Light Truck", SAE 2007-01-4151, University of Michigan, 2007.

[17]R. Ramakrishnan, Somashekhar S. Hiremath and M. Singaperumal. Theoretical investigations on the effect of system parameters in series hydraulic hybrid system with hydrostatic regenerative braking. The Journal of Mechanical Science and Technology, 26(5):1321-1331, 2012.

[18]Kruse R.E., T.A. Huls, "Development of the Federal Urban Driving Schedule," SAE Paper No. 730553, 1973.

[19]ModeFRONTIER, Version 3.1.0, ESTECO, Trieste, Italy.

[20]Bäck T., Evolution Strategies Module R1.1 for ModeFRONTIER., Technical Report 2004-05. 